\title{
EL PENSAMIENTO RIZOMÁTICO EN LA CONSTRUCCIÓN DE UN MODELO DIDÁCTICO QUE VIVENCIE LA FORMACIÓN INTEGRAL EN EL ESQUEMA DE EDUCACIÓN VIRTUAL DE LA UNIVERSIDAD SANTO TOMÁS BUCARAMANGA
}

\author{
Gonzalo Camacho Vásquez \\ Magister en Educación Pontificia Universidad Javeriana, \\ Diplomado en Pedagogía para la investigación Pontificia Universidad Javeriana \\ y estudiante de Doctorado en Educación de la Universidad Norbert Wiener. \\ Docente de la Universidad del Tolima en el programa de Licenciatura en Inglés \\ gcamachv@outlook.com
}

\begin{abstract}
Resumen
Mucho se ha dicho respecto a los conceptos de educación virtual y formación integral. Sin embargo, pocos cruces se han establecido entre estos dos discursos con el fin de vislumbrar nuevos retos que la pedagogía debe enfrentar en la nueva era tecnológica. La educación virtual parece privilegiar el desarrollo de las competencias cognitivas. En primera instancia, se hace un repaso histórico de la manera como la tecnología ha establecido nuevos retos a la educación, desde la invención de la imprenta hasta la aparición del Internet. Posteriormente, se analizan los diferentes discursos producidos respecto a los dos conceptos propuestos, mediante la aplicación de la Arqueología del Saber de Michel Foucault. Hecho esto, se pasa a analizar la manera como se concibe la formación integral en las rutas de aprendizaje que hacen parte de las aulas virtuales. Posteriormente, se conecta la idea de formación integral con el pensamiento rizomático propuesto por Gilles Deleuze. Finalmente, se plantean visibilidades de la educación integral en el esquema de la educación virtual a través de preguntas que llevan a re-pensar el modelo pedagógico tomasino.
\end{abstract}

Palabras clave: formación integral, educación virtual, filosofía tomasina, modelo de aprendizaje, pensamiento rizomático.

\footnotetext{
Abstract

Lot of ideas has been produced regarding the concepts of e-learning and holistic training. However, few of them establish a relation between both discourses in order to find new challenges pedagogy faces in this new technological age.

The growing technological advances bring new ways of conceiving education. E-learning seems to privilege the development of cognitive competencies. In the first part of the article, it is made a historical review on the way te-
}

chnology has set new challenges to education from the invention of the first printing machine until the apparition of Internet and the digital age. Then the different produced discourses on the field of e-learning and holistic training are analyzed by applying the Archeology of Knowledge proposed by Michel Foucault. After this, the author shows the way Holistic training is evidenced in the learning routes that are part of the virtual rooms. Afterwards, the idea of Holistic training is connected to the proposal of rizomatic thinking by Gilles Deleuze. Finally, new sights for the Thomas de Aquinas pedagogical model with regards to the e-learning are shown, through some problematic questions.

Key words: Holistic training, E-learning, Thomas Aquinas philosophy, learning model, rizomatic thinking.
"En esta edad eléctrica, cada vez más, nos vemos traducidos en forma de información al mismo tiempo que nos acercamos a la extensión tecnoló- gica de la conciencia". Marshall McLuhan (1994)

\section{1. ¿Puede la relación histórica entre tecnología y educación dejar ver las limitantes en el desarrollo de la formación integral?}

Pareciera que los grandes cambios en los dispositivos pedagógicos están marcados por los desarrollos tecnológicos a lo largo de la historia de la humanidad. La invención de la imprenta (1448-1450) de Johannes Gutenberg se convierte en el gran salto hacia la difusión en masa 
del conocimiento. Este invento no sólo hizo posible acelerar el proceso de confección de los libros, los cuales eran manuscritos elaborados por los monjes, sino que también logró sacar el conocimiento de los conventos y claustros religiosos. Si bien es cierto que los discursos de los primeros libros tipografiados se circunscribían al tema religioso (específicamente La Biblia), la invención de la imprenta permitió la generación de un pensamiento diferente que, poco a poco, dio origen al humanismo y al enciclopedismo y posibilitó la transmisión de teorías que marcaron la historia de la humanidad; entre éstas se encuentran El Modelo Heliocéntrico de Copérnico (1543), la Ley de Gravitación Universal de Newton (1687), y La teoría de la evolución del hombre de Charles Darwin (1859).

La invención de la radio y su masificación como medio de comunicación (1873 -1920) trajo consigo, junto con la educación por correspondencia, la primera idea de Educación a Distancia. Aunque éstas en un principio fueron unidireccionales o con respuesta y retroalimentación a largo plazo, se con-virtieron en las primeras prácticas que sacaron la educación del territorio físico de las Instituciones escolares o educativas, al separar al docente y al alumno y establecer el aprendizaje autónomo. La comunicación entre docente y estudiante se hizo posible mediante la implementación de cuadernos de trabajo y guías didácticas; sin embargo, este esquema no contemplaba la interacción entre alumnos, lo que para Vigotsky en su Teoría Socio-histórica se constituye en la principal razón de ser de la escuela. Cole (1992) al explicar los postulados básicos de la Teoría sociohistórica menciona que las funciones psicológicas humanas difieren de los procesos psicológicos de otros animales porque los primeros tienen mediación cultural, poseen un desarrollo histórico y crecen a partir del desarrollo de actividades prácticas. Para este autor, el aprendizaje es eminentemente social en la medida en que la construcción de sentido a través del lenguaje sólo es posible en la interacción con

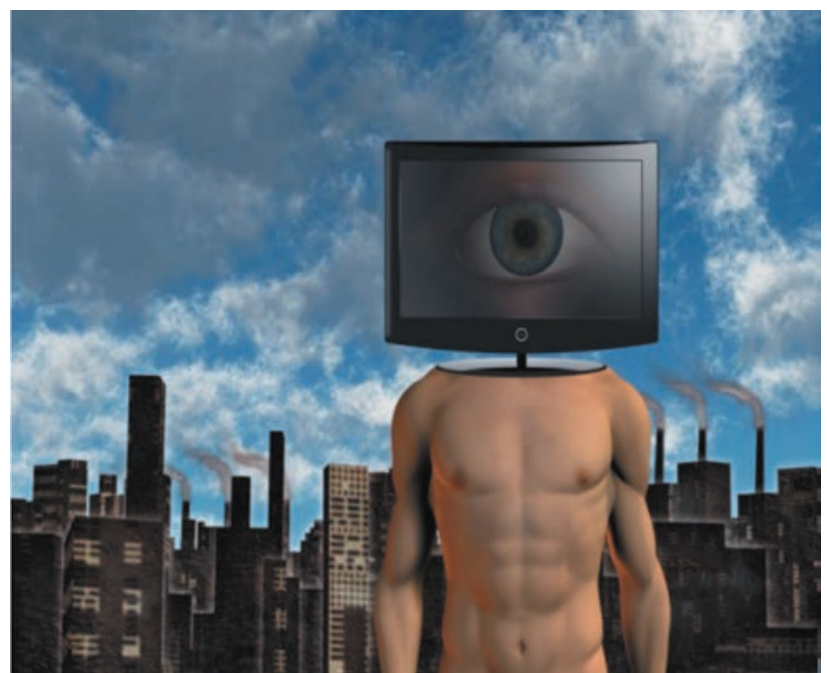

(imagen en línea)Obtenido de www.shutterstock.com Rolff, B. (2005) City man.

los demás. De este modo, los primeros asomos de la educación a distancia, no contemplan la interacción de los alumnos entre sí, lo que para Viogtsky se constituye en un elemento esencial en la construcción del conocimiento. Posteriormente se verá cómo puede incidir este aspecto en los propósitos de la Educación Integral.

Si bien la aparición de la televisión, y su utilización con fines educativos, agregó dinamismo y estímulo visual, siguió con las mismas limitantes de la radio y la correspondencia en cuanto a inmediatez de la retroalimentación y la interacción social. De otro modo, parece evidente la influencia que ha traído la televisión en el pensamiento de las sociedades. Su carácter inicialmente informativo ha pasado a convertirse en un medio poderoso de aprendizaje que incluso puede afectar más la mente de sus receptores que lo que puede hacer un docente en su aula de clases. A pesar que la televisión en este momento comparte su trono con el Internet en cuanto a capacidad de afectación del pensamiento, esta primera es aún el medio de mayor difusión de ideas a personas de todas las edades. De manera espontánea, un televidente con subscripción a televisión satelital o televisión por cable puede tener acceso a mayores fuentes de información y, por consiguiente, al conocimiento de manera más efectiva que ningún otro medio con capacidad de influencia 
en el pensamiento humano. La influencia de la televisión y los medios masivos de comunicación es tal que Marshall McLuhan ha dado por denominarlas "the extensions of man". Joost Van Loon (2008) critica la manera como los medios de comunicación han llegado a afectar el pensamiento de los individuos hasta la instancia de cortar la capacidad del hombre para usar el pensamiento con el fin de pensar la influencia medios, esto debido a que los medios estructuran el propio pensamiento:

"Thinking about media is something we cannot do often enough. This is first of all because not only do we think 'through' media; media also structure our thinking (Curtis 1977). How we think is so closely bound to the media through which this thought is processed and by which this thought is generated, that we generally do not perceive thought as itself mediated. Hence, we normally take media for granted. It is in our very nature to take media for granted because as Marshall McLuhan (1964) provocatively said: media are 'the extensions of man [sic]"

Así, en este esquema de educación la imagen de un mediador que guíe la estructura de pensamiento y lleve a una posición crítica frente a la información presentada es nula. Un televidente puede acumular de manera inconsciente información sin criterios claros que lo lleven a discernir o tomar una posición crítica. Tampoco existe lo que Jerone Bruner (1996) en su"Toward a Theory of Instruction Ilama "Exploration of alternatives" Esta exploración de alternativas se resume en tres términos: "activation", "maintenance" y "direction".

Es difícil pensar que un esquema de educación por televisión haga posible la presencia de "ese algo" que activa, mantiene y direcciona el aprendizaje evitando el libre albedrío del zapping, por ejemplo.

Finalmente, el desarrollo tecnológico hacia la era digital y la creación del Internet (La red informática mundial 1989-1992) hicieron posible el surgimiento de la noción de "educación virtual". Como lo enuncian Aparici y Silva (2012), la aparición del Internet terminó con las limitantes de comunicación existente entre alumnos y docente en los anteriores dispositivos tecnológicos:

"Radicalmente distinta de la televisión como máquina restrictiva, centralizadora y articulada a partir de la transmisión de informaciones elaboradas por un centro de producción, la Red se presenta como un sistema abierto a los interactuantes que permite la autoría y la co-creación en el intercambio de información y la construcción del conocimiento. En este escenario sociotécnico, ocurre la transición de la lógica informacional del modelo «uno-todos» (modelo transmisivo) a la lógica de la comunicación «todos-todos» modelo (interactivo)." (51-58)

De este modo, la limitante que presentaba la televisión en los procesos de formación en cuanto a la imposibilidad de interacción de los estudiantes, es subsanada por la herramienta virtual. Los Sistemas de Administración del Aprendizaje (Learning Management Systems) poseen herramientas tales como los foros asincrónicos y los chats sincrónicos que permiten la retroalimentación por parte del docente y la colaboración entre estudiantes, por ejemplo.

En este recorrido de la imprenta al Internet se han suplido las necesidades y dispositivos que requiere cualquier proceso de aprendizaje; sin embargo, la formación integral parece no ser una preocupación explícita en los diferentes momentos tecnológicos reseñados. Se ha enfatizado y mejorado aspectos tales como la interacción que con la radio y la televisión eran limitados. Si bien el Internet se muestra como la plataforma ideal para la virtualización de la educación, aún en esta instancia del análisis nos queda la pregunta eje de esta reflexión:

¿Es posible con todos estos avances tecnológicos de nuestra época llevar al desarrollo de la 
formación integral (algo que es difícil de lograr aún en la presencialidad)?

¿Cómo se da la Formación Integral en la Educación Virtual?

¿Cómo favorecer el desarrollo de aspectos tales como la responsabilidad o la proyección social desde un esquema no-real?

Es importante aclarar que las preguntas en el artículo están planteadas desde el enfoque problemático propuesto inicialmente por Michel Foucault y desarrollado por Gilles Deleuze en la Lógica del Sentido (Lichilín, 1999, pp. 5-18). En esta lógica el problema se compone de tres series: la serie de las ideas (compuesta por los conceptos y las imágenes), la serie de los acontecimientos y la serie de las preguntas. Las preguntas vinculan los conceptos y las imágenes presentes en las ideas buscan la paradoja que deja ver los acontecimientos. Para Deleuze, las preguntas no pretenden ser resueltas, sino que funcionan como giros del pensamiento que permiten crear visibilidades mediante nuevas preguntas con el fin de mantener vivo el problema.

\section{2. ¿Qué nuevas visibilidades frente al problema expuesto, nos deja ver el} cruce entre los discurso de Formación Integral y Educación Virtual?

El análisis histórico entre tecnología y educación nos permitió ver la manera como los avances han permitido mejorar la calidad del aprendizaje-enseñanza, sin embargo, aún no podemos ver con más detalle cómo se da la formación integral en el estado de desarrollo de la virtualidad actual

En este apartado se propone analizar los discursos sobre Educación virtual y Formación integral al apelar a la Arqueología del saber.

¿Qué se entiende por "Educación virtual"? Para entender este enunciado, se realizará un

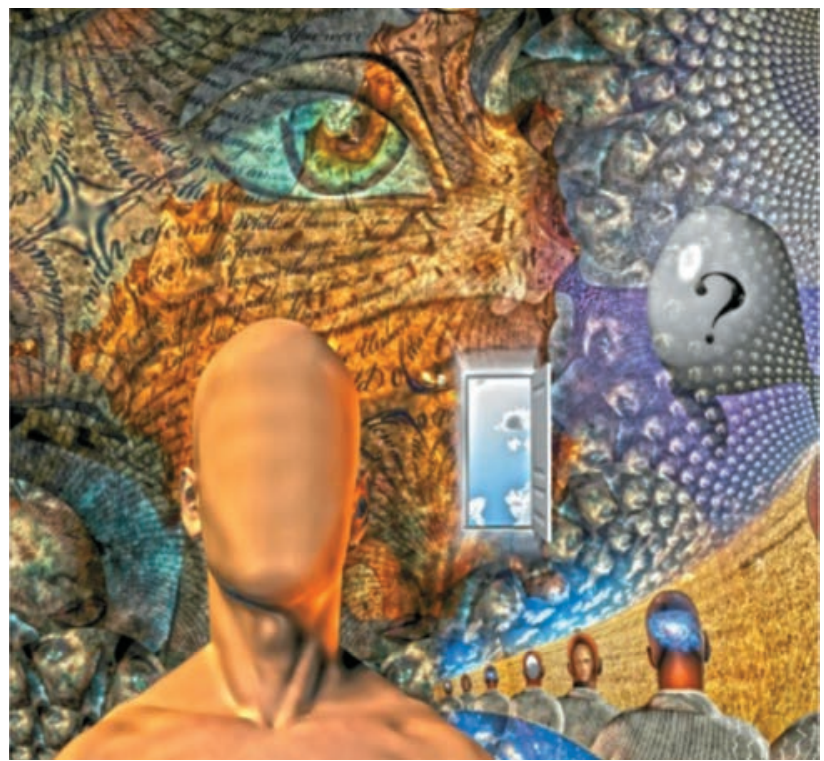

(imagen en línea)Obtenido de www.shutterstock.com Rolff, B. (2005) Human dream like a scene in organic windows.

rastreo de los discursos y se apela a la Arqueología del saber (Deleuze G, 1987) La Arqueología del saber distingue tres espacios en el discurso: El espacio colateral o adyacente, el cual relaciona el enunciado con otros enunciados que hacen parte del mismo grupo. El espacio correlativo trata la relación del enunciado con sus sujetos, sus objetos y sus conceptos. El espacio complementario o de formaciones no discursivas, el cual asocia el enunciado con instituciones, acontecimientos políticos, prácticas y procesos económicos. Así, en el espacio colateral o adyacente la noción de educación virtual está asociada a otros enunciados tales como "relación educativa de carácter interpersonal", "espacio de formación apoyado en Tecnologías de la información y la comunicación", "modalidad de educación a distancia", "educación en línea" y "desarrollo de programas en el ciberespacio", entre otros

Recordemos la pregunta que nos ocupa en este artículo:

¿Es posible con todos estos avances tecnológicos de nuestra época llevar al desarrollo de la formación integral?

Para vislumbrar posibles respuestas a esta pregunta, necesitamos saber lo que se quiere 
decir al enunciar "la formación integral". Desde la perspectiva tomasina, la Formación Integral se asocia con una "visión cristiana de vida", "el desarrollo de todas las dimensiones del ser", una "visión de totalidad", un "obrar moralmen- te", una "educación total", una "opción ética personalista", "una actitud sociopolítica". Podríamos resumir lo expresado en el Proyecto Educativo Institucional (2004, p. 19-36)) de la Universidad mediante el siguiente gráfico

RESPONSABILIDAD: Capacidad de respuesta, "deber ser" moral o jurídico

\author{
CAPACIDAD \\ MORAL \\ "Todo hombre \\ debe ser para \\ todo hombre un \\ familiar y amigo" \\ Proyección Social
}

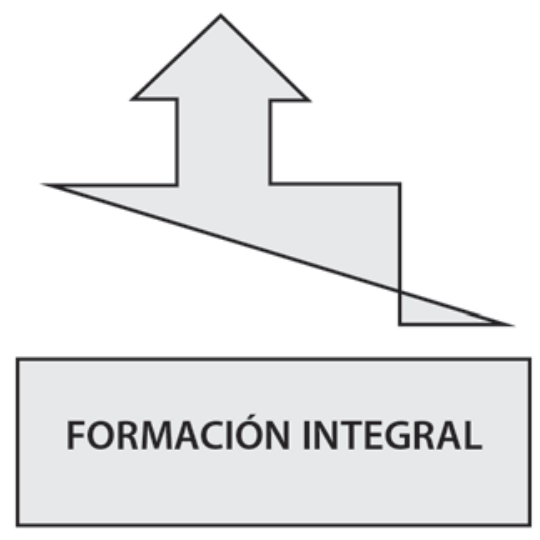

CAPACIDAD CRÍTICA

Pensamiento problémico, primacía del conocer sobre el pensar, capacidad de juicio
CREATIVIDAD

"Inventio"
Así las cosas: ¿Qué resultaría del cruce de los discursos de "Educación Virtual" y "Formación Integral"? ¿Qué se ha dicho respecto a la formación integral en la educación virtual?

El rastreo bibliográfico arroja resultados que analizan las dos nociones por separado. De los pocos estudios que las asocian podemos mencionar la que aparece en el texto "Modelo de aprendizaje virtual para la educación superior MAVES" (2012)

"La EV (Educación Virtual) es un sistema educativo abierto que propende por la formación integral, con énfasis en la autogestión del aprendizaje a través de diversos medios, mediaciones y acciones pedagógicas que articulan la experiencia del estudiante, las necesidades y potencialidades de los entornos socioculturales y el saber académico, para la permanente significación y transformación individual y colectiva (Zambrano, 2012, p.11)"
En este aparte discursivo, se puede apreciar que la noción de formación integral es asociada a la idea de desarrollo de la autonomía del aprendiz en cuanto a la capacidad de aprender. Si se analiza este concepto a la luz de la noción de formación integral desde la visión tomasina, se ve que sólo apunta a una de las dimensiones del ser.

De igual manera, se puede ver cómo el autor asocia la noción objeto de análisis con otras dimensiones del ser, tales como la biosocial, cognitiva y psicosocial. Sin embargo, ésta tampoco satisface la noción tomasina de Formación Integral:

"La educación en el Maves está ligada al ser, desde sus dimensiones del desarrollo biosocial, cognitivo y psicosocial, las cuales inciden en el proceso educativo del estudiante, la ausencia de una de ellas limita su construcción pues afecta su formación integral. La educación se relaciona con el proceso de 
aprendizaje (tiempo de estudio), acceso a materiales, calidad de los profesores, pertinencia del currículo, gestión administrativa y contexto social" (Zambrano, p. 130)

Pero entonces: ¿Qué le falta a estas definiciones? Lorenzo García Arieto (2006) al mencionar los inconvenientes y dificultades de la educación a distancia señala:

"Igualmente otros objetivos de ámbito afectivo y actitudinal, formación y cambio de actitudes de los alumnos, así como los del área psicomotriz que no atienden a necesidades que se expresen por escrito, se suelen lograr de manera más efectiva mediante los contactos personales, aunque no olvidemos la fuerza de la TV (distancia) para modificar, por ejemplo, actitudes referidas al voto en unas elecciones." (87-88)

Queda la pregunta: ¿Cómo desarrollar procesos afectivos y actitudinales desde un esquema de educación virtual? ¿Se ha pensado al respecto?

Aunque el Proyecto Educativo Institucional enuncia claramente las acciones tendientes a asegurar la formación integral, podríamos sospechar que éstas tengan un efecto sustancial en la vida de los educandos:

"La Universidad Santo Tomás no solamente atiende la formación filosófica, ética, política, a través de las asignaturas que el "Estudio General" ofrece a todas las carreras y que forman parte fundamental de cada plan de estudios de formación profesional, al que se integran cátedras de democracia, de un idioma extranjero y de deportes, sino que multiplica las acciones comunitarias abiertas a todas las facultades, para activar otros intereses: foros, debates, actividades pastorales, actividades estéticas, cultura física, deportes (...)." (p. 64).

Vale la pena preguntarnos si estas actividades reseñadas en el PEI logran desarrollar aspectos relevantes en la formación del ser tales como la "visión cristiana de vida", el "obrar moralmente", la "opción ética personalista", y la "actitud sociopolítica" que tienen que ver con el ámbito afectivo y actitudinal.

Se puede reconocer que este problema investigativo objeto del presente artículo no pertenece solamente al ámbito educativo de la Universidad:

"La realidad es que si los alumnos estudian para sacar un título y que ese título les permita encontrar un trabajo y todos los estamentos participan de ese montaje (alumnos, padres, profesores, instituciones educativas), entonces no podemos pedirle a la educación que solucione los problemas que decimos que nos importan: formar ciudadanos críticos, solidarios y democráticos preparados para combatir la delincuencia, la xenofobia, la violencia familiar, la pedofilia, la desigualdad, (...)" (Martínez, 2004, p. 35)

Parece existir en el pensamiento colectivo la idea de educación asociada directamente a la idea de capacitación para alcanzar un puesto laboral, pues deja en lo subyacente la formación integral. Por consiguiente, y parafraseado Foucault, se puede decir que para que exista un cambio en las prácticas es necesario primero realizar este cambio en el discurso. Si bien no existen estudios sobre la efectividad del discurso de la formación integral en la vida de los educandos en la modalidad presencial, podríamos afirmar que la mayoría de las veces éste pertenece al currículo oculto de cada cátedra y el grado de afectación depende de la disposición particular de cada educador. Entonces: ¿Se puede correr el riesgo de una menor afectación en el esquema de educación virtual? ¿Podría el esquema de educación virtual llevar a un énfasis en el desarrollo del conocimiento per se, y descuidar la formación del ser? ¿Qué nuevos retos plantea la educación virtual a la formación integral? ¿Estamos destinados a caer en esa "extensión tecnológica de la conciencia" de la que habla McLuhan? 


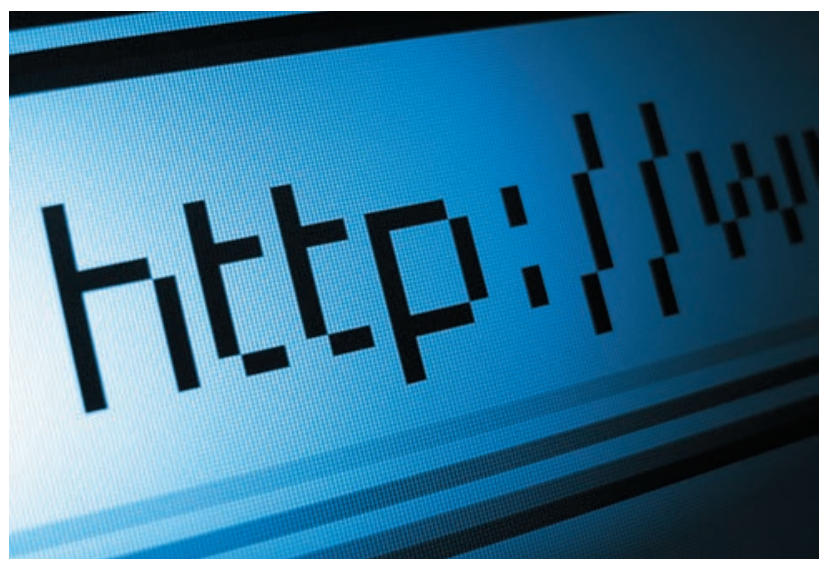

Imagen http://www.morguefile.com/archive free photos

Al respecto, expresa Cardona Ossa (2003) que la educación busca dentro de sus objetivos últimos la formación integral del ser humano, entendido como un ser de necesidades, habilidades y potencialidades, que actúa en las dimensiones cognitivas (conocimientos) axiológicas (valores) y motoras (habilidades y destrezas), para mejorar la calidad de vida. Por ello, la nueva "Era de la Información" obliga a la educación a cambiar desde sus bases para conseguir en los estudiantes una formación integral y como parte de ella, la habilidad de "aprender a aprender, a hacer, a vivir y a convivir". (Cardona Ossa, p. 74)

Queda la pregunta: ¿Qué implica un cambio de la educación "desde sus bases"? ¿Qué cambios son necesarios realizar en el discurso de la didáctica de los diferentes programas de formación que se evidencien en el comportamiento ético, modo de obrar, compromiso sociopolítico, y la sensibilidad de los educandos?

Desde la perspectiva del espacio correlativo (la relación del enunciado con sus sujetos, sus objetos y sus conceptos), no se pregunta:

¿Quiénes hablan en los enunciados sobre Educación virtual y formación integral?

¿A quién o quiénes están dirigidos estos discursos? ¿Por qué se habla de formación integral y educación virtual? ¿En qué otros discursos (documentos, artículos, enunciados) se menciona la formación integral?
Se podría atrever a decir que en las diferentes nociones de Formación Integral habla el Estado. Desde una visión de dispositivo de poder, el Estado aparece como un macro-poder que dispone de los sujetos mediante micro-poderes. Estos micro-poderes están representados en instituciones tales como la Iglesia, las Escuelas, los hospitales, los distritos militares que son los encargados de hacer cumplir las disposiciones estatales (Foucault, 1998, p. 87)

La ley General de Educación de Colombia o Ley 115 de 1994 promulga en su artículo 5 sobre los fines de la educación:

“El pleno desarrollo de la personalidad sin más limitaciones que las que le imponen los derechos de los demás y el orden jurídico, dentro de un proceso de formación integral, física, psíquica, intelectual, moral, espiritual, social, afectiva, ética, cívica y demás valores humanos." (Ley General de Educación, p. 2)

La aparición de la preocupación por una formación integral parece no ser gratuita. Antes de la aparición de la teoría de las Inteligencias múltiples de Howard Gardner (1989), se creía que el aprendizaje giraba en torno a lo netamente cognitivo, así la inteligencia se solía medir con un test I.Q. (Intelectual Quotient) que solamente evaluaba la capacidad mental para procesar información en su mayoría desde un dominio netamente de pensamiento lógico y racional. Las prácticas educativas llevaban a crear bachilleres y profesionales con grandes capacidades para reproducir el conocimiento, pero limitados al momento de aplicarlo a problemas reales de su contexto, incapaces de relacionarse socialmente o de vincular el saber a una misión ética con el planeta.

El discurso de Gardner parece haber sido adoptado o adaptado a los preceptos religiosos de las diferentes comunidades religiosas. Es difícil creer que Santo Tomás, San Ignacio de Loyola o San Juan Bautista de la Salle hablaran específicamente de formación integral. La teoría 
de Gardner coincide con aspectos tales como la formación humanista de Santo Tomás de Aquino en la inteligencia interpersonal, la reflexión o introspección ignaciana tomada de los Ejercicios Espirituales de Ignacio de Loyola concatena con la inteligencia intrapersonal, por ejemplo.

¿Se podría pensar que hubiese sido al revés, que Gardner toma los principios religiosos de estas comunidades para crear su teoría? Existe la posibilidad, sin embargo, el carácter científico de la teoría de Gardner hace posible la justificación de la formación integral como una política de Estado, más allá de una justificación poco pluralista como pudiese haber sido hablar de la pedagogía ignaciana o tomasina en una ley general de educación.

\section{La formación integral desde el análisis}

\section{discursivo de las rutas de aprendizaje de cátedras en esquema virtual}

El presente apartado lleva a analizar la pregunta: ¿En qué otros discursos (documentos, artículos, enunciados) se menciona la formación integral? Desde las rutas de aprendizaje que hacen parte de las aulas virtuales de la Universidad Santo Tomás, Bucaramanga.

El análisis según informe sobre la incorporación de Aulas Virtuales (Rueda A. \& Caicedo R, 2012) en los procesos de enseñanza presencial del segundo semestre de 2012, la Universidad Santo Tomás Bucaramanga, a través de la Oficina de Educación Virtual asesoró pedagógica y tecnológicamente un total de 303 aulas virtuales, de las cuales 10 son de esquema bimodal (50\% presencial y $50 \%$ virtual), 26 son de esquema $100 \%$ virtual y 267 son presenciales con apoyo virtual.

Para propósitos de análisis, se tomarán dos aulas en esquema $100 \%$ virtual y se procederá a analizar las competencias contempladas en sus planes de asignatura y su concreción en las actividades planteadas en las correspondientes rutas de aprendizaje.
Para claridad de los lectores, se precisa que el esquema pedagógico contempla el diseño de un plan de asignatura con formato común a todas las cátedras que se dictan en los diferentes programas de formación profesional. De estos planes de asignatura se desprenden los planes de clase o rutas de aprendizaje en el caso de las aulas con componente virtual. El plan de asignatura presenta los siguientes componentes: metas de aprendizaje, problemas (desde el enfoque problémico), competencias, las teorías y conceptos, metodología, evaluación y recursos.

Las aulas catalogadas como $100 \%$ virtuales, paradójicamente pertenecen al Departamento de Humanidades y están dentro de la categoría de cátedras transversales, es decir, son aquellas que enseñan la filosofía institucional. Entre ellas se encuentran:

4 aulas de Cultura de la información, 4 aulas de Emprendimiento, 4 aulas de Educación Ambiental, y 4 aulas de Derechos Humanos.

El aula de Derechos Humanos contempla dentro de sus competencias genéricas la siguiente:

"Reconoce los derechos humanos como elementos constitutivos de la sociedad contemporánea, en la cual el individuo es el centro del accionar del Estado promoviendo la reflexión sobre su implicación en la vida cotidiana desde una perspectiva humanista."

Según esta competencia, se pretendería desarrollar la capacidad moral y crítica mediante su vinculación con el concepto "derechos humanos", desde la perspectiva humanista que tiene que ver con la noción de "ética personalista", reseñada en la definición de formación integral en el apartado II de este artículo.

¿Cómo se evidencia el desarrollo de esta competencia en las rutas de aprendizaje?

Al revisar las competencias contenidas en 
las rutas se evidencia la predilección que se da a las competencias específicas que se relacionan con desarrollos cognitivos y teóricos de la asignatura, más en ninguna de ellas se toma la competencia genérica analizada.

En el caso de la asignatura virtual de Emprendimiento, se encuentra la siguiente competencia:

Demuestran dominio en los conocimientos teóricos y prácticos de los saberes y pre-saberes del emprendimiento y los aplica con sentido ético y responsabilidad social como empresario con el fin de tener un empoderamiento dentro del mercado.

La parte de la competencia que hace referencia a la formación integral es la que aparece subrayada. Se suscitan las siguientes preguntas:

¿Cómo se puede evidenciar que el estudiante aplique los conocimientos teóricos con sentido ético y responsabilidad social?

¿Es posible evidenciar y medir aspectos relacionados con el desarrollo ético y moral? ¿Se deberían medir?

Supuestamente, las actividades de aprendizaje deben permitir ver el desarrollo de estos aspectos perteneciente a la "Capacidad moral" de la formación integral tomasina.

En la ruta de la sección 1 “Cómo crear una empresa productiva?" se incluye la competencia anteriormente enunciada, sin embargo, las actividades propuestas parecen no llevar de manera consciente al desarrollo del componente ético. En la actividad 1, el docente propone la resolución de un cuestionario por parte de los estudiantes en que se controla la lectura de varios documentos. La mayoría de preguntas apuntan a comprobar que los estudiantes hayan asimilado los contenidos teóricos. En la plataforma Moodle en la que diseña el aula virtual, los docentes tienden a privilegiar los cuestiona- rios de escogencia múltiple con única o varias respuestas o de opción falso verdadero, ya que estos permitan la autoevaluación. El desarrollo de procesos de formación ética requeriría de otros instrumentos de aprendizaje que utilicen, a cambio, la pregunta abierta, el debate, la disertación, lo cual implica mayor inversión de tiempo en la elaboración por parte de los estudiantes y la retroalimentación por parte del docente. La actividad 2 de la ruta se desvía hacia la construcción de un diagnóstico de la idea de negocio que hace parte de un trabajo que se debe entregar al final del semestre, la actividad 3 es un foro que podría ser el escenario propicio para debatir el aspecto ético, sin embargo, se proponen las siguientes preguntas:

“QQué barreras e implicaciones tiene una persona cuando toma la decisión de ser empresario? ¿El empresario nace o se hace?

Puede ser que en la discusión del foro se lleguen a tocar aspectos de la formación humanista, no obstante en estas preguntas se percibe mayor preocupación por el terma per se, en lugar de hacer más evidente el desarrollo de la competencia que hace parte de este recorrido.

¿Si se fuese consciente del desarrollo de la competencia, qué tipo de preguntas se podría plantear?

Esta "conciencia" nos podría llevar a analizar situaciones de negocios locales en su compromiso con el sentido ético y la responsabilidad social, por ejemplo: ¿Qué impacto tiene en la comunidad de los barrios del norte de Bucaramanga, la existencia de empresas cementeras? Dentro del plan de emprendimiento de estas fábricas, ¿Qué medidas se toman para proteger el medio ambiente y la salud de los habitantes de esta región? ¿Cómo asumiría usted como nuevo empresario la responsabilidad social y el sentido ético?

De este modo, cátedras como la de emprendimiento llevarían al estudiante a utilizar conocimientos de otras asignaturas tales como 
Derechos Humanos o Educación Ambiental que hacen parte de la transversalidad de la Universidad para pensar y concientizar en que emprendimiento no es sólo "hacer empresa" sino también asumir un compromiso ético con la sociedad.

Entonces, el ejercicio docente pasaría a ser lo que Deleuze denomina un "agenciamiento".

"Todo eso, las Líneas y las velocidades mesurables, constituye un agenciamiento (agencement). Un libro es precisamente un agenciamiento de ese tipo, y como tal inatribuible. Un libro es una multiplicidad. Pero todavía no sabemos muy bien qué significa lo múltiple cuando cesa de ser atribuido, es decir, cuando es elevado al estado de sustantivo. Un agenciamiento maquínico está orientado hacia los estratos, que sin duda lo convierten en una especie de organismo, o bien en una totalidad significante, o bien en una determinación atribuible a un sujeto; pero también está orientado hacia un cuerpo sin órganos que no cesa de deshacer el organismo, de hacer pasar y circular partículas asignificantes, intensidades puras, de atribuirse los sujetos a los que tan sólo deja un nombre como huella de una intensidad" (Deleuze G. \& Guattari F, 2002, p. 10)

La educación desde la noción de agenciamiento pasaría a abandonar el esquema de armario con cajones en donde se guarda el conocimiento y se cierra al final de cada clase, de cada lección, de cada Unidad, para convertirse en un organismo movido por la fuerza de la intensidad. Esta intensidad la entiende Deleuze a la manera de Spinoza, como una dimensión de afectación que va más allá de las composiciones físicas para tocar las conformaciones intrínsecas de los objetos. Así, la manera de disponer el saber transgrede la dinámica de la fragmentación en espacios y tiempos para hacer caso al deseo, a la intuición que le da sentido desde la singularidad del sujeto. Entonces, la educación abandonaría el armario para pasar a establecer relaciones "rizomáticas" entre los saberes.

"El rizoma procede por variación, expansión, conquista, captura, inyección. Contrariamente al grafismo, al dibujo o a la fotografía, contrariamente a los calcos, el rizoma está relacionado con un mapa que debe ser producido, construido, siempre desmontable, conectable, alterable, modificable, con múltiples entradas y salidas, con sus líneas de fuga" (Deleuze G. \& Guattari F, p. 26)

La formación integral no sería un órgano más del cuerpo educativo, sería una especie de sangre que recorre todos los territorios de ese cuerpo. El pensamiento rizomático es abierto, es cambiante, se mueve en la dinámica territorialización-desterritorialización. El pensamiento es una especie de Patología Superior" en el que éste se definiría como perverso, problemático, poético y paradójico. Perverso porque es desviado de sus fines pretendidamente "naturales", comprometido únicamente con la aventura de su propio viaje- con su decisión de medirse con lo impensable, de alcanzar aquello que sólo puede ser pensado. Problemático en el sentido que establece una relación trilógica entre las ideas, la pregunta y los acontecimientos.

\section{Visibilidades en la construcción de un modelo didáctico que vivencie la formación integral}

Para construir un modelo pedagógico que sea recorrido por el flujo de la formación humanista y poder hablar de una "formación integral" se haría necesario, en primera instancia, conocer el funcionamiento del dispositivo pedagógico actual. Visto como dispositivo o agenciamiento, el Proyecto Educativo de la Universidad Santo Tomás sería un mecanismo o un territorio compuesto de líneas duras, líneas flexibles y líneas de fuga. Las primeras hacen referencia a aquellos segmentos que están predeterminados socialmente, sobre-codificados por el Estado. Serían aquellos componentes del currí- 


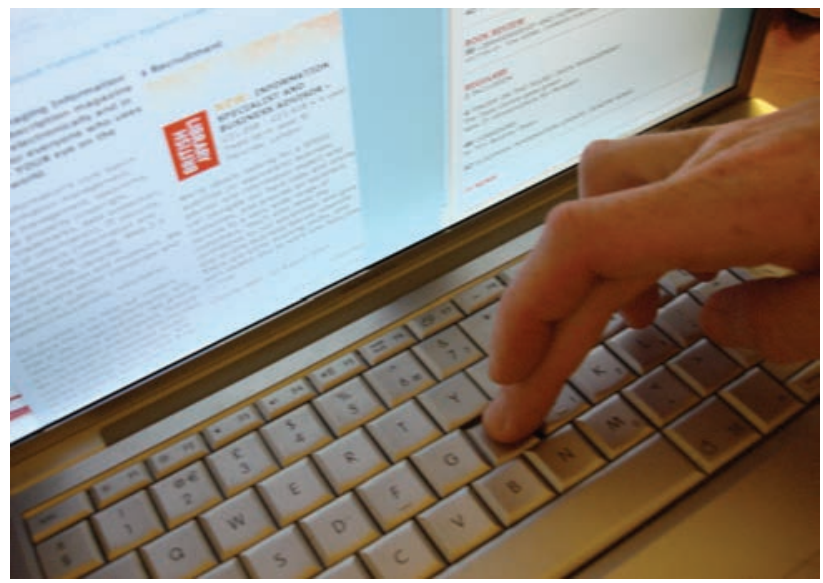

Imagen http://www.morguefile.com/archive free photos

culo que estarían dentro de lo "no negociable". El ámbito de un "pensamiento de la diferencia" se atrevería a transgredir el orden puesto por las líneas duras, a dudar, a desquebrajar, a hacer grieta para poder ver aquello que se niega a ver. Este resquebrajamiento es el que convierte las líneas duras en líneas flexibles para producir una re-territorizalización. Las líneas de fuga están en medio de las líneas duras y las líneas flexibles y son la posibilidad de re-inventarse, de soñar, de permitirse pensar nuevos modos de. Estas líneas de fuga son generalmente los "atajos" para saltar la rigidez de las líneas duras, es el niño que lanza papeles, que hace avioncitos en la clase para escapar del esquema, de la monotonía de la falta de "afectación". La línea dura llevaría al docente de esta clase a castigar al estudiante, a aplicarle el Manual de Convivencia. Por el contrario, la línea flexible lo llevaría a cuestionarse, a pensar sobre aquello que rutiniza y a generar un Acontecimiento. Este sería lo contrario a lo que ocurre cotidianamente y se hace único en un hecho que lleva a pensar nuevas maneras de hacer.

¿Cuáles serían esas "líneas duras" en el agenciamiento pedagógico tomasino? ¿Se está dispuesto a pensar las "líneas duras" y generar a partir de su cuestionamiento una investigación centrada en el pensamiento de la diferencia, más allá de estudios estadísticos y de justificación del dispositivo actual? ¿Cómo podríamos llegar a flexibilizar el currículo para introducir cambios que re-territorialicen la educación y la ubiquen en el campo de lo integral? Si la formación integral difícilmente se vivencia en las clases presenciales, más allá del discurso moral: ¿Cómo vivenciarla en un esquema virtual? ¿Cómo convertir el acto pedagógico en una "ética", es decir, en una manera de ser, de obrar con relación al saber?

¿Qué "líneas de fuga" son los avioncitos que dan una alerta, que no se debería llevar a endurecer el dispositivo, sino a dar la posibilidad de re-pensarlo, de darle la vuelta, de desarmarlo y re-armarlo?

En conclusión, el presente artículo reflexivo con las preguntas planteadas, lleva a ver, más que a responder:

El desarrollo tecnológico mejora el aprendizaje al permitir otras mediaciones pedagógicas, diferentes al maestro, tales como las herramientas multimediales que posibilitan la exploración de las potencialidades de los aprendices en sus estilos de aprendizaje particulares mediante la activación de sus canales sensitivos.

La formación integral vista como un mecanismo de poder, se percibe como un discurso que pretende la creación de un modelo de ciudadano competente en todas sus dimensiones como condición para una mejor fuerza de obra calificada.

La educación virtual podría permitir el desarrollo del modelo integral desde la autonomía, pero deja mucho que desear en cuanto al compromiso ético, humano y social. Basados en el análisis de las aulas virtuales de la USTA, se evidencia un marcado énfasis en la transmisión de contenidos mediante desarrollos cognitivos.

La vivencia de una formación integral desde lo virtual a partir de la noción de "rizoma" de Deleuze implicaría ver el proyecto educativo como un agenciamiento compuesto de líneas duras, flexibles y de fuga, cuyo desenmarallamiento nos conduzca a mirar la formación inte- 
gral en función del saber, a manera de torrente que recorre todo el acto educativo, más allá de un cuerpo constituido de órganos.

\section{Referencias Bibliográficas}

Aparici, R. y Silva, M. (2012) Pedagogía de la Interactividad. Revista Científica de Educomunicación. Está indicado: XIX, 2012. ISSN: 1134-3478; páginas 51-58

Bruner, J. (1996) Notes on a Theory of Instruction. En Toward a Theory of Instruction. Cambridge: Harvard University Press. Pp. 42-43.

Cardona Ossa, G. "Tendencias Educativas para el Siglo XXI Educación Virtual, Online y @learning elementos para la discusión". Edutec. Disponible en: http://edutec.rediris.es/Revelec2/revelec15/cardona.pdf (16 de Mayo de 2003).

Cole M. (1992) Cognitive development and formal schooling: The evidence from cross-cultural research. En Moll L. Vigotsky and Education. Instructional Implications and Applications of Sociohistorical psychology. New York: Cambridge University Press.

Colombia, Congreso de la República de Colombia (1994) Ley General de Educación. Obtenido el 25 de febrero de 2013 en: http://www.alcaldiabogota.gov. co/sisjur/normas/Norma1.jsp?i=292

Deleuze G. (1987) Foucault Un nuevo Archivista (“La Arqueología del Saber") En: Foucault. Barcelona: Paidós. Pp. 27-48.

Deleuze G. \& Guattari F (2002) Mil Mesetas, Capitalismo y Esquizofrenia. Valencia: Pre-textos.

Foucault, M (1998) Historia de la Sexualidad I. La Voluntad del Saber. Madrid: Siglo Veintiuno Editores. P. 87

Gardner, H., \& Hatch, T. (1989). Multiple intelligences go to school: Educational implications of the theory of multiple intelligences. Educational Researcher, 15(8), 4-9.

García Arieto, L (2006) La Educación a distancia. De la Teoría a la práctica. Barcelona: Editorial Ariel. Pp. 87-88.
Gardner, H., Lichilín, A (1999) La Construcción del Problema y la Lógica del Sentido. Segundo Módulo Serie Investigación. Maestría en Educación. Campo de Profundización en Educación para la Convivencia. Bogotá: Javegraf. Pp. 5-18.

Martínez J. (2004). El e-learning y los siete pecados capitales. Revista Intangible Capital. Está indicado: No. 5 Vol. 0. Pp. 1- 56

McLuhan M. (1994). Comprender los Medios de Comunicación. Las Extensiones del Ser Humano. Buenos Aires: Ediciones Paidós Ibérica S.A.

Moll, L. (1992).Vigotsky and Education. Instructional Implications and Applications of Sociohistorical Psychology. New York: Cambridge University Press.

Paradigma Pedagógico Ignaciano. Reflexiones educativas y pedagógicas con inspiración ignaciana. Disponible en: http://www.javeriana.edu.co/Facultades/ Educacion/08/docs-generales/REFL-PED-IGN.pdf

Rueda A. \& Caicedo R, (2012). Informe sobre la Incorporación Aulas Virtuales en los Procesos de Enseñanza Presencial. Segundo Semestre de 2012.

Universidad Santo Tomás (2004). Proyecto Educativo Institucional. Bogotá, D.C. Tercera Edición.

Van Loon, J. (2008). Media Technology: Critical Perspectives.Buckingham, GBR: Open University Press, 2008. p4.Disponible en: http://site.ebrary.com/lib/bibliotecausta/Doc?id=10229873\&ppg=17 Copyright (c) 2008. Open University Press. All rights reserved

Zambrano Ayala, W. (2012) Modelo de aprendizaje virtual para la educación superior MAVES: basado en tecnologías Web 3.0.Colombia: Ecoe Ediciones, 2012. p ?. Disponible en: http://site.ebrary.com/lib/bibliotecaustasp/Doc?id=10552704\&ppg=22 Copyright $@$ 2012. Ecoe Ediciones. All rights reserved.

\section{Cómo citar este artículo:}

Camacho, V. G. (2013). El pensamiento rizomático en la construcción de un modelo didáctico que vivencie la formación integral en el esquema de educación virtual de la Universidad Santo Tomás Bucaramanga.

Espiral, Revista de Docencia e Investigación. 2 (2), 91-102 